\title{
DIVERS@!
}

\section{AS AGÊNCIAS MULTILATERAIS, OS MUNICÍPIOS E OS DESAFIOS DO DESENVOLVIMENTO LOCAL NO BRASIL}

\author{
Bruno Antonio Banzato ${ }^{3}$
}

Sérgio Tadeu Gonçalves Muniz ${ }^{4}$

\begin{abstract}
RESUMO
O presente artigo tem como objetivo principal entender como as agências multilaterais influenciam o desenvolvimento local. Desenvolvimento local é um novo modo de promover desenvolvimento que prioriza as necessidades das comunidades locais sem deixar convergir com o contexto global. No Brasil, os municípios são um recorte local que possibilita um estudo sustentável. Após a Constituição de 1988, os governos locais encontraram na cooperação com as agências multilaterais uma alternativa para suprir a demanda de seus cidadãos. Este artigo observará as condições de tais acordos e seu impacto nas políticas públicas.
\end{abstract}

Palavras chave: Desenvolvimento local. Agências Multilaterais. Políticas Públicas.

\section{Introdução}

Tendo em vista que as cooperações internacionais vêm se consolidando como um importante instrumento para os governos locais solucionarem as demandas de seus cidadãos, principalmente aquelas que exigem grande volume de recursos, a proposta deste artigo é entender as práticas das agências internacionais e sua influência no desenvolvimento local.

Para tal é necessário contextualizar o problema, procurando entender o conceito de desenvolvimento local, bem como sua inserção no meio global, apresentado no primeiro

\footnotetext{
${ }^{3}$ Bacharel em Relações Internacionais, mestrando em Planejamento e Governança Pública da UTFPR, Brasil. E-mail: banzato@gmail.com
}

${ }^{4}$ Graduado em Ciências Econômicas, mestrado em Desenvolvimento Econômico, doutorado em Engenharia de Produção, docente e coordenador do Curso de Pós-Graduação em Planejamento e Governança Pública, UTFPR, Brasil. E-mail: sermuniz@utfpr.br

Divers@! Revista Eletrônica Interdisciplinar/Matinhos/Vol.7, n.1, p. /Jan./jun./2014. 


\section{DIVERS(a)!}

tópico. Neste momento, debate-se como essa interação não diminui as relações de proximidade, mas, ao contrário, as reforça, tendo em vista que as estratégias podem gerar ganhos para os atores envolvidos no processo de desenvolvimento local.

No segundo tópico, é feita uma análise das dificuldades dos municípios brasileiros após a Constituição de 1988 tendo em vista que os municípios assumiram novas atribuições e responsabilidades, atuando como agente de desenvolvimento, porém não dispõe de recursos e capacidade técnica suficientes. Neste caso, agências de fomento internacionais se tornaram uma opção viável para os municípios tanto no que se refere ao financiamento de projetos quanto à execução de políticas públicas.

Para concluir, é feito um relato sobre as práticas dos organismos internacionais ao firmar cooperação com os governos locais, com destaque as chamadas "condicionalidades", ingerências que interferem na gestão e no impacto das políticas públicas junto a população. O alto volume de recursos internacionais recebidos representa o esforço dos municípios para atacar raízes dos problemas que ameaçam as cidades.

Esse artigo foi adaptado do referencial teórico da dissertação (??) e foi concebido através de uma pesquisa bibliográfica a fim de contribuir para delimitar um campo referencial de conhecimento sem a ambição de proporcionar uma revisão de literatura exaustiva e esgotar o assunto.

\section{Desenvolvimento Local e os Municípios}

Desenvolvimento local é um processo endógeno capaz de promover o dinamismo econômico e a qualidade de vida em pequenas unidades territoriais ou em uma população com características específicas. Ele transforma a organização social local a partir da mobilização da comunidade e seus atores em torno de um projeto coletivo, que deve sustentar e viabilizar politicamente determinadas prioridades e orientações básicas de desenvolvimento. (BUARQUE, 1999)

O desenvolvimento local tem o compromisso moral de focar seus interesses no homem, a partir das potencialidades, limitações e especificidades de cada região por melhores condições de vida. Ultramari e Duarte (2011) explicam que deve haver prioridade na formação de novas molduras socioeconômicas buscando a sustentabilidade e construindo uma cidadania participativa.

Sobre a importância da dimensão local. Andion (2003) explica:

Divers@! Revista Eletrônica Interdisciplinar/Matinhos/Vol.7, n.1, p. /Jan./jun./2014. 
Os estudos da nova geografia socioeconômica vêm mostrar que o local não é apenas mais uma dimensão do desenvolvimento, e sim o locus privilegiado em que ocorre de fato esse desenvolvimento. O espaço local contém o passado (história), mas também as possibilidades futuras de construção de uma nova realidade, a partir da participação dos atores e do uso dos próprios recursos existentes no local (desenvolvimento endógeno). (ANDION, 2003, p. 1044)

Buarque (1999) afirma que o desenvolvimento local não é um fenômeno isolado. Graças à atual conjuntura de globalização e intenso processo de transformação, é necessário integrá-lo com o contexto regional e nacional, a fim de garantir que as mudanças externas, de qualquer ordem, se traduzam em efetivo desenvolvimento, internalizando vantagens sociais, econômicas e culturais para a população local.

Essa abordagem mais ampla é denominada por Franco (1998) como "desenvolvimento local integrado e sustentável", no qual uma nova dinâmica socioeconômica é capaz de potencializar resultados em virtude das parcerias interinstitucionais que podem ser celebradas. Isso ocorre a partir do local, do encontro de ações do Estado e da sociedade - independente do seu tamanho -, e da convergência e integração das políticas e dos programas coincidentes. Assim, o conceito de local adquire a conotação de alvo socioterritorial das ações.

Desenvolvimento econômico, social, cultural, político e institucional, organização físico-territorial e gestão ambiental fazem parte da abrangência do desenvolvimento local integrado e sustentável. O autor propõe que há um consenso sobre esse conceito:

Desenvolvimento local integrado e sustentável é um novo modo de promover o desenvolvimento, que possibilita o surgimento de comunidades mais sustentáveis, capazes de suprir suas necessidades imediatas, descobrir ou despertar suas vocações locais e desenvolver suas potencialidades específicas, além de fomentar o intercâmbio externo, aproveitando-se de suas vantagens locais. (FRANCO, 1998, p.07)

Franco (1998) enfatiza que o conceito local não é sinônimo de pequeno e não se refere necessariamente à diminuição ou redução. Pelo contrário, a maioria dos estudiosos da questão concorda que o local não é um espaço micro, podendo ser tomado como um município ou, inclusive, como uma região compreendendo vários municípios. 


\section{DIVERS(Q)!}

Buarque (1999) concorda que o município, por sua escala territorial restrita e por seu corte político-administrativo, é um espaço privilegiado de estudo de desenvolvimento local. O autor explica que com a descentralização o município e a comunidade devem ser transformados em catalisadores das forças econômicas e energias sociais, através da síntese e convergência da atuação de diferentes instituições estaduais, regionais e nacionais.

Com isso, o autor adverte que o corte municipal não pode levar a um isolamento do âmbito territorial restrito, ignorando o contexto social, econômico e, principalmente, ecológico, no qual está inserido e com o qual se estabelece uma relação de interação e intercâmbio. (BUARQUE, 1999).

A maioria dos setores que apostam nas potencialidades do desenvolvimento local integrado e sustentável não toma o local como contraposto ao nacional, ou mesmo ao global. Por exemplo, uma focalização no espaço municipal ou regional dispensaria o papel das políticas nacionais concebidas e operadas no âmbito da União. Franco (1998) afirma que parece haver consenso em torno da orientação segundo a qual as políticas nacionais devem ser desenvolvidas conjunta e democraticamente com aquelas que visam estimular o desenvolvimento local, uma vez que os atores locais não dispõem de um conjunto de informações necessárias, nem tampouco contam com condições suficientes para atuar sobre todas as variáveis que determinam o comportamento econômico e social, inclusive da própria localidade onde se situam.

Uma tendência de fragmentação das ações no plano local pode acontecer se o peso dos problemas e interesses locais levarem a visões e decisões da sociedade excessivamente localizadas e isoladas das condições e determinações do contexto, diminuindo a importância das iniciativas estratégicas. Buarque (1999) explica que essa tendência reforçada pelos limites de informação das sociedades locais, restringe a eficácia das iniciativas e programas de desenvolvimento, pela falta de percepção dos processos globais em que o local está inserido. 
O local e o municipal são subsistemas de um sistema mais amplo e global, de tal modo que os problemas e as potencialidades municipais e locais dependem de fatores externos e das condições do contexto. O município e a comunidade (assentamentos) constituem cortes importantes de autonomia de gestão, mas devem estar articulados com os macroespaços, demandando um esforço de coordenação, com instâncias e mecanismos capazes de exercer o papel articulador na distribuição de responsabilidades no espaço, numa espécie de descentralização coordenada. (BUARQUE, 1999, p. 26)

Andion (2003) complementa afirmando que essa interação do local com o global não enfraquece as relações de proximidade, mas ao contrário, as reforça, pois leva à definição de estratégias de adaptação que exigem a promoção da solidariedade local e a ampla participação dos atores envolvidos.

Entretanto, Buarque pondera que quanto menor a escala espacial das decisões, maiores tendem a ser a influência das forças locais e a proximidade da estrutura de poder. "Como é sabido, nos planos municipal e local domina uma cultura política tradicional, clientelista, paternalista e autoritária, controlada pelas oligarquias, que passariam a assumir o controle das políticas e atividades descentralizadas" (BUARQUE, 1999, p. 26).

Por outro lado, Franco (1998) defende que o argumento básico a favor do desenvolvimento local é muito simples: é na esfera municipal que os problemas são melhores identificados e, portanto, torna-se mais fácil encontrar a solução mais adequada. $O$ atendimento das necessidades da sociedade, o aproveitamento das potencialidades locais e das habilidades existentes é facilitado pela maior proximidade das comunidades. Ainda, garante-se maior continuidade das ações em função do controle social exercido pela sociedade.

Para Andion (2003), a partir da década de 1980, o conceito e a prática do desenvolvimento se redefinem. De um processo conduzido pelo Estado, de maneira centralizada, planificada e tecnicista, visando o crescimento econômico seletivo de algumas regiões, o desenvolvimento passa a ser visto e praticado de outra forma, valorizando a capacidade local de analisar suas especificidades e a autonomia administrativa para buscar sua sustentabilidade em contexto macro. Para compreender esta mudança é importante destacar alguns conceitos-chave, propostos pela autora, que caracterizam e delimitam a noção de desenvolvimento na atualidade: 
A sustentabilidade, que dá origem ao termo desenvolvimento durável ou sustentável; o território, que é a base da noção de desenvolvimento local; a participação cidadã, que favorece a inclusão da sociedade civil como protagonista do processo de desenvolvimento e o desenvolvimento com base em valores, que implica atrelar os fins econômicos do desenvolvimento à proteção de bens e valores sociais, políticos, culturais e ambientais. (Andion, 2003, p. 1041)

"O desenvolvimento local aceita a ideia de haver áreas isoladas de sucesso em meio a regiões e países extremamente pobres" (ULTRAMARI; DUARTE (2011), p.24) concluem Ultramari e Duarte (2011), ao entenderem que as mudanças macroeconômicas internacionais e a constituição de mercados em escala global têm impactado, nas últimas décadas, as economias locais e regionais, enfraquecendo o papel dos estados e estimulando a descentralização. De acordo com os autores, o poder local viu suas atribuições e responsabilidades alteradas, exigindo que este passasse a atuar como agente de desenvolvimento. Isso explicaria o fato do município ser considerado capaz de transformar positivamente a sua sociedade.

Porém os autores ponderam:

(..) o poder local também necessita de um envolvimento do poder nacional em suas iniciativas. Tal envolvimento não significa, necessariamente, uma participação direta nas iniciativas, mas sim, na definição de diretrizes e de subsídios financeiro e técnico.(ULTRAMARI;DUARTE, 2011, p.32).

Para operacionalizar essas novas responsabilidades que municípios passaram a assumir, ao se encontrarem também como agente de desenvolvimento, fez-se necessário o relacionamento com mecanismos multilaterais de fomento e de execução de políticas públicas. Essa relação dos órgãos locais com agências globais é analisada a seguir.

\section{Os Municípios e as Agências Multilaterais}




\section{DIVERS(a!}

A Constituição de 1988 proporcionou um processo de descentralização tendo como pano de fundo o debate sobre a reforma do Estado pós-regime militar e o cumprimento de uma agenda neoliberal. Esse movimento de redistribuição do poder foi bastante complexo e refletia a necessidade de reestruturação do pacto federativo e das competências federais, estaduais e municipais quanto às atividades de planejamento, gestão e controle de serviços públicos (COELHO, 2000). A Constituinte de 1988 acabou culminando para os municípios a chamada "autonomia limitada", que, segundo Coelho (2000, p.04), é a capacidade limitada que os municípios têm de exercer influência sobre as esferas estaduais e federais de governo. Esse isolamento fica evidente numa clara divisão institucional do trabalho: enquanto as diretrizes gerais do desenvolvimento urbano cabem à União (vide o Pacto das Cidades); a legislação do direito urbanístico compete às esferas federal e estadual; ao poder municipal fica a execução das políticas públicas de desenvolvimento urbano.

Stephanou (2005, p. 132) explica que a nova Constituição Brasileira redefiniu a hierarquia do direcionamento, formulação e execução das políticas públicas:

O governo federal passou a assumir, então, de forma prioritária, a coordenação de políticas públicas, e os municípios assumiram grande parte da execução dessas políticas. Essa postura levou a uma nova gestão das políticas públicas, onde [sic] muitas das responsabilidades e recursos, que eram somente de instância federal, foram distribuídas para governos estaduais e municipais, ainda que com muita resistência, pela forte tradição federal de, muitas vezes, tratar de forma desigual alguns estados e municípios. (STEPHANOU, 2005, p. 132)

Assim, percebe-se que, após 1988, as políticas públicas deveriam ser concebidas e implementadas de baixo para cima, orientadas pelos grandes objetivos e estratégias nacionais sem deixar de estar a serviço do desenvolvimento local.

Além de definir a divisão entre as esferas, a Constituição Federal de 1988 autoriza que a União concentre aproximadamente $60 \%$ da arrecadação, restando $25 \%$ para os estados e apenas $15 \%$ para os municípios. Somado a esse fato está a ausência de garantia de provisão desses repasses intergovernamentais, o que contribui para um cenário desfavorável de implantação de políticas públicas de desenvolvimento local de longo prazo - que demandam uma capacidade de investimento municipal (PINTO, 2005).

Sobre os repasses intergovernamentais, Teixeira $(2002$, p. 06) ressalta: 
Apesar do aumento de sua capacidade financeira, a participação dos municípios na receita tributária global não supera os $18 \%$ ou $20 \%$. No entanto, eles assumem vários encargos e responsabilidades das outras esferas, o que os obriga a negociar recursos nos diversos programas federais ou estaduais. Com uma frágil base econômica, ao lado da ineficiência administrativa, os recursos próprios na maioria dos municípios não vão além dos $5 \%$ do total da receita. Dessa forma, a autonomia de realizar políticas próprias sem vinculação aos programas federais e estaduais é mínima.(TEIXEIRA, 2002, p. 06)

Essa dependência dos programas federais dificulta o desenvolvimento local, porque, apesar de coerentes na sua formulação, nem sempre atendem às especificidades das necessidades locais. (FRANCO, 1998)

Ainda nessa campo, Ultramari (2001) afirma que há uma ausência de esforços de formulação de políticas urbano-ambientais nacionais devido à falta de continuidade nas estruturas político-administrativas federais para o trato das questões das cidades, que coloca sob o rol de responsabilidade dos municípios - ou seja, dos poderes locais, o desafio de oferecer soluções estruturais, sociais e ambientais aos brasileiros.

Moisés (1999) lista alguns processos cujos municípios brasileiros participam, porém Ihes escapam do controle direto, aqui transformado em quadro:

Quadro 1 - Processos cujos municípios brasileiros participam

\begin{tabular}{|c|}
\hline $\begin{array}{l}\text { Processo de urbanização acelerada; pressão social sobre a oferta de infraestrutura e } \\
\text { serviços públicos e sobre espaços adequados à ocupação e uso; demanda por emprego e } \\
\text { renda. }\end{array}$ \\
\hline $\begin{array}{l}\text { Municipalização das políticas sociais, sob modelo que articula três esferas do Poder } \\
\text { público, e que institui fundos e conselhos setoriais com participação social. }\end{array}$ \\
\hline $\begin{array}{l}\text { Acirramento da competição entre diferentes lugares, para a recepção de investimentos } \\
\text { privados e públicos. }\end{array}$ \\
\hline Aparecimento de uma nova esfera entre o público e privado: o público não-estatal. \\
\hline $\begin{array}{l}\text { Globalização econômico-produtiva: revolução tecnológica e gerencial; aumento da } \\
\text { interdependência econômica e da complexidade do sistema mundial; enfraquecimento da } \\
\text { capacidade regulatória dos Estados nacionais; desemprego estrutural; exigência de maior }\end{array}$ \\
\hline
\end{tabular}




\section{DIVERS(a)!}

Intensificação do uso do conhecimento e da informação; flexibilidade da produção; eficiência organizacional baseada no conceito de sistema; descentralização; controle de resultados.

Abertura econômica, plano real, queda da inflação, desequilíbrio das contas públicas, enfraquecimento do potencial de investimento público nas três esferas de governo, privatizações, ataques especulativos à moeda, reforma previdenciária, administrativa, fiscal e política.

Fonte: Adaptado de Moisés (1999, p. 05)

Esse quadro geral coloca os desafios que se expressam nos diversos municípios de forma muito peculiar. Depende de seu tamanho e porte populacional, sua situação geográfica, geopolítica e ambiental e seu perfil de atividades produtivas. Há uma dificuldade em trabalhar principalmente as questões relativas à economia, reconhecendo-se que é limitado o poder de intervenção do município e ostensiva a falta de recursos em suas administrações - na maioria das vezes, insuficiente, mesmo para o trato das questões emergenciais (ULTRAMARI; DUARTE, 2011).

Moisés (1999) aponta algumas das muitas atribuições dos municípios brasileiros:

O Poder Público municipal é o principal protagonista na área de saúde pública e de educação pré-escolar e fundamental. É ele, também, o responsável por serviços públicos da maior relevância para a saúde ambiental e a qualidade de vida, como a coleta, o tratamento e a disposição de resíduos, o abastecimento de água e o esgotamento sanitário. Realiza obras de drenagem e de abertura e conservação de vias públicas e estradas vicinais. $E$ pode realizar o licenciamento ambiental de empreendimentos de impacto local e desenvolver (ou não) programas de combate à erosão, proteção de mananciais, controle do uso de agrotóxicos, educação ambiental etc. (...) Coletar, tratar e disponibilizar informações é um imperativo da Administração. (...) Quanto ao desenvolvimento territorial, é ao Poder Público municipal que compete a elaboração, implementação e fiscalização de códigos e planos locais de organização territorial, de uso dos espaços públicos e de proteção ambiental, como a lei de zoneamento, o código ambiental, de obras, de posturas etc. (MOISÉS, 1999, p. 08)

O isolamento e dependência de repasses intergovernamentais; crescimento e transformação econômica das cidades; e as disputas por investimentos privados, que restringem a possibilidade de aumento de tributação municipal, são fatores que propiciam a 


\section{DIVERS(a)!}

tomada de empréstimos junto a organismos multilaterais por parte dos governos locais (GOLDENSTEIN, 2001).

Nesse contexto, de acordo com Barros e Cesário (2008), os municípios encontram terreno fértil para a atuação em âmbito internacional, já que a maioria dos bancos e agências internacionais ligadas ao sistema de cooperação das Organizações das Nações Unidas (ONU) pauta suas ações na premissa de fortalecimento do poder local. Os autores avaliam que a interface global-local está em voga e a chance de engendrar e executar projetos através de recursos externos está acima de qualquer crise internacional.

Assim, a busca de recursos para viabilizar ações de implantação de políticas urbanas ultrapassam as barreiras nacionais e as agências internacionais de fomento, com juros barato e crédito disponível para o Brasil, se tornaram uma opção natural de financiamento de políticas públicas locais através de projetos e programas formulados e implementados em parceria. (BARROS E CESÀRIO, 2008)

Essa atuação dos municípios brasileiros na busca de novas fontes de recursos para o seu desenvolvimento em âmbito internacional se situa dentro de um fenômeno batizado pelo direito internacional de "Cooperação Descentralizada", em que governos subnacionais (estados e municípios) e demais atores da esfera local passam a ter relevante papel no cenário internacional a despeito da atuação do governo central, com o propósito de proporcionar um desenvolvimento socioeconômico sustentável na esfera local (BARROS; CESÁRIO, 2008). Isso ocorre através da Cooperação Técnica Internacional, que, pela definição de Soares (1994, p. 170), é a transferência de recursos entre países, seja de forma bilateral ou multinacional.

Para a Organização das Nações Unidas (ONU), a Cooperação Internacional não é uma ação meramente humanitária ou assistencial: ela deve priorizar o progresso econômico das nações menos favorecidas. Soares (1994, p. 170) explica que não se trata de humanitarismos para ajudar Estados carentes e muito menos de intervenções a fim de legitimar os interesses dos países desenvolvidos em países menos favorecidos. Antes de tudo, a Carta das Nações Unidas prevê o direito ao desenvolvimento por parte dos Estados emergentes e também o dever de cooperação por parte dos países industrializados.

Dentro desse parâmetro, a cooperação descentralizada é tida como novo modelo de Cooperação Internacional porque entendem os governos subnacionais como "sujeitos da cooperação" e não mais como meros recebedores de assistência. Nessa instância, os governos locais devem atuar como catalizadores de conhecimentos técnicos para atender às demandas apresentadas por todos os atores que compõe a população que representa. Entende-se que a cooperação descentralizada consiste em uma relação substancial Divers@! Revista Eletrônica Interdisciplinar/Matinhos/Vol.7, n.1, p. $\quad$ /Jan./jun./2014. 23 


\section{DIVERS(a)}

colaborativa, que implica trocas e compartilhamento de saberes entre os atores locais e as instituições internacionais. Portanto, a participação e engajamento da comunidade devem ser estimulados por seus representantes, afinal quem poderia ser mais capacitado para avaliar a efetividade e viabilidade do projeto local financiado por recursos externos que os próprios benefeciados, avaliam Barros e Cesário (2008).

Atualmente os municípios brasileiros administram 52 projetos com recursos das agências multilaterais, o que representa exatamente US\$ $1.499 .944 .354,00$ em financiamentos e doações. (MINISTÉRIO..., 2012).

Sobre a interação internacional dos municípios, o presidente da Confederação Nacional dos Municípios, Paulo Ziulkoski declarou, em 2011:

[...]Foi por meio da interação internacional que pudemos perceber quão criativas são as políticas locais brasileiras. Somos exemplos no mundo inteiro, sendo o único país que reconhece na sua Constituição a autonomia das unidades municipais. Da mesma forma que somos demandados por diferentes partes do globo, temos a oportunidade de buscar no meio internacional soluções e recursos para nossos dilemas (CONFEDERAÇÃO NACIONAL DOS MUNICÍPIOS, 2011, p.8).

O Banco Mundial e o Banco Interamericano de Desenvolvimento são alguns dos principais órgãos que se destinam a prover assistência concessional aos países em desenvolvimento e que no Brasil têm um relevante papel entre os municípios, já que são os que mais financiam políticas públicas - cerca de $80 \%$ dos projetos de cooperação internacional registrados na Secretaria de Assuntos Internacionais (MPOG) são dessas instituições (MINISTÉRIO..., 2012). De forma geral, esses dois órgãos financeiros multilaterais têm, em suas linhas gerais, propostas aos países objetivadas na redução da pobreza, na promoção da equidade social, na modernização do Estado, na integração regional e no desenvolvimento sustentável (STEPHANOU, 2005, p.128).

Os municípios os procuram, apresentam seus projetos e negociam diretamente com os órgãos, que por sua vez analisam e selecionam os projetos de acordo com as suas exigências e linhas de crédito disponíveis. Sobre isso, Stephanou (2005) ressalta que está clara, nos documentos estratégicos das agências multilaterais, a prioridade em financiamentos a projetos que garantam uma boa gestão, tragam reformas necessárias ao bom desempenho do setor público e estabeleçam impactos significativos à população. Esses impactos são entendidos como a relação entre a implementação de um programa e seus resultados. 


\title{
DIVERS(a)
}

A autora afirma ainda que as agências buscam cada vez mais aprimorar o sistema de avaliação dos projetos financiados por elas, por isso em todas as etapas, desde a sua implementação até a avaliação de resultados, os projetos passam por constantes auditorias e intervenções para verificar o grau de cumprimento dos termos do acordo pelos países tomadores de empréstimos. Segundo as estratégias de desenvolvimento, salientadas em relatórios oficiais das agências, há uma necessidade de reformas estruturais dos tomadores de empréstimos. Somente através desse processo que se pode garantir o atendimento das exigências impostas e a consecução mais eficaz e efetiva de programas públicos, avalia Stephanou. (2005, p.156)

As agências também contam com um vasto acervo de pesquisa e reflexão sobre políticas públicas e meio ambiente e existe uma enorme capacidade de pesquisa nessa área (VIANNA JR, 1998, P. 80). Dessa forma, a atuação das agências nas cooperações internacionais sobrepõe o aspecto meramente de financiador: elas atuam como parceiras dos gestores locais na elaboração de políticas públicas de desenvolvimento urbano. Vianna Jr (1998) explica:

\begin{abstract}
Além da importante função meramente financeira, os bancos têm atuado como "inteligência" auxiliar do Governo na elaboração de programas e projetos, como, por exemplo, os programas responsáveis por políticas de ajuste estrutural, os projetos setoriais de desenvolvimento, os de combate à pobreza... Desse modo, parte das novidades em políticas públicas e projetos do governo brasileiro é, muitas vezes, o resultado de um trabalho de cooperação internacional em que o Banco Mundial e o BID têm um relevante papel (VIANNA JR, 1998, p.82).
\end{abstract}

Porém essa "inteligência auxiliar" é motivo de críticas entre vários estudiosos do assunto. Fiori (2006) reconhece a importância das instituições financeiras multilaterais ao suprir a demanda por financiamento de políticas públicas desde o início dos anos 1980, porém destaca que os projetos de desenvolvimento econômico e de política urbana postulados e financiados por bancos como o BID e o Banco Mundial carregam consigo diversas "condicionalidades", determinantes de uma agenda afirmativa que modela um padrão de uso dos recursos públicos e de organização do Estado. De acordo com o autor, essas instituições priorizam as chamadas políticas públicas de "mercado" em substituição às políticas públicas de caráter universal, dentro de uma concepção neoliberal de desenvolvimento do setor privado e crescimento econômico local.

Fiori (2006) ainda critica a gestão desses projetos, pontuando que há muitas irracionalidades nos padrões de financiamento externo para políticas públicas, como a 


\section{DIVERS(a)}

gestão estatal terceirizada formada por técnicos privados, gerenciadoras de projeto, ONGs e consultores pagos com recursos do tomador, além dos contratos que não são fechados em moeda nacional e sim estrangeira, vulnerabilizando a gestão dos recursos que sofrem o impacto das oscilações cambiais.

Na mesma linha crítica, Adauto Herculano Guesser (2005) pondera que a assessoria técnica dos bancos adéqua as propostas enviadas pelos governos aos modelos de políticas públicas que querem ver reproduzidas no âmbito local e, assim, acabam determinando a aplicação e eleição das políticas públicas a serem implementadas, configurando a instauração de um pensamento único, no qual não se abre espaço para alternativas - ou seja, os bancos multilaterais acabam tendo forte influência na condução das políticas públicas pelos governos tomadores.

Sobre as interferências das agências multilaterais de desenvolvimento, Fiori salienta:

Mesmo quando os gestores públicos percebem algumas das irracionalidades envolvidas nesse padrão de financiamento, pouco ou nada é feito para mudar a situação. Os contratos com os bancos multilaterais são, muitas vezes, defendidos por uma visão instrumental, a qual não mede as consequências reais (financeiras, políticas e sociais). Parece que estamos diante de um piloto automático que, uma vez acionado, faz o empréstimo externo, e mesmo a interferência das instituições multilaterais nas políticas públicas aparecem como algo desejável (FIORI, 2006, p.07).

Sobre este comportamento que conduz a determinadas imposições dos bancos aos países-membros, Stephanou (2005) analisa que, apesar das muitas críticas, no caso brasileiro elas se justificam principalmente quanto à capacidade do Estado em cumprir certas tarefas fundamentais e básicas na formulação e implementação de políticas públicas, pois muitos projetos apresentados às agências de financiamento sequer asseguram a sustentação dos objetivos propostos na sua implementação. A autora ressalta também que há falta de recursos para garantir uma burocracia de qualidade com melhor gestão - ainda mais existindo um embate constante com os padrões clientelistas e corporativos das políticas públicas no país.

Viana e Fonseca (2011) criticam os programas de empréstimos do BID porque, ao adotar uma série de medidas impositivas que incluem as chamadas "boas práticas" (best practices) gerenciais, sobretudo na fase de preparação e implementação de seus projetos, os municípios compactuam com uma estratégia generalizadora de procedimentos, sobretudo do ponto de vista administrativo e gerencial. Assim, o BID replica essa técnica em todos os seus projetos, independentemente da geração conflitos entre o sistema administrativo local e a implementação das "melhores práticas" requeridas pelo Banco.

Divers@! Revista Eletrônica Interdisciplinar/Matinhos/Vol.7, n.1, p. /Jan./jun./2014. 
Desse modo, a forma de atuação do BID gera dificuldades burocráticas que resultam por vezes no baixo desempenho de programas por ele financiados. Ademais, ao concentrar seus esforços na gestão, o Banco torna mais distante a participação da "sociedade civil" nos projetos, pois, uma vez que suas ações concentram-se nos aspectos gerenciais, fortalece sua lógica de procedimentos em detrimento da maior permeabilidade da sociedade politicamente organizada na definição do uso dos recursos emprestados. (Viana e Fonseca, 2011, p. 202)

Portanto, as estratégias utilizadas pelo Banco não apenas se distanciam da sociedade como podem cooperar para que seus resultados sejam insatisfatórios, especialmente sobre as políticas sociais que atuam diretamente com a população. A consequência desse processo, tendo em vista a importância do BID - em termos de recursos emprestados e da tipologia de agenda que possui -, refere-se à queda da importância dos direitos sociais e à necessidade de o Estado intervir, apenas reativamente, aos mais diretamente atingidos. (VIANA E FONSECA, 2011)

Para Viana e Fonseca (2011), isso ocorre em razão de, estruturalmente, as políticas financiadas pelo Banco serem descompromissadas das necessidades sociais dos mais pobres e, portanto, impactando negativamente no desempenho econômico local.

\section{Considerações Finais}

O desenvolvimento local é um processo que prioriza as necessidades da população através de um projeto coletivo e de forma sustentável. Ele garante ampla participação dos atores locais através de uma aproximação das estruturas de poder com a comunidade, o que proporciona um bom nível de controle social e, consequentemente, uma continuidade das ações governamentais.

Para ser efetivo, o desenvolvimento local deve convergir com o contexto global de acordo com as diretrizes em nível nacional. Essa inserção deve observar as necessidades locais e a competitividade num macrocontexto.

Os municípios são um bom recorte a nível local no Brasil. Após a constituição de 1988 eles ganharam autonomia e mais responsabilidades, porém não recebem recursos federais e estaduais na mesma proporção. 


\section{DIVERS(a)}

Diante dos repasses intergovernamentais insuficientes aos municípios, as instituições financeiras multilaterais não só financiam políticas públicas no Brasil, como também interferem na elaboração e execução dos programas e projetos apresentados pelos governos locais. Isso acontece através de condicionalidades que influenciam ou até determinam a aplicação da política pública por parte dos governantes, modelando a agenda de desenvolvimento do poder local.

Se, por um lado, os municípios podem absorver práticas de gestão pública mais eficientes e conhecer experiências internacionais de implementação de políticas públicas, por outro, a população perde devido as exigências das agências multilaterais baseadas no foco exagerado na gestão e não nos resultados. A preocupação pelo bom uso do recurso financeiro se sobrepõe a aspectos ligados a sustentabilidade daquelas ações junto ao público beneficiário.

Como sugestão para a superação das limitações dessa pesquisa, propõe-se estudos de casos que relatem as minunciosidades das experiências dessas parcerias entre as agências multilaterais e os municípios no Brasil.

\section{Referências}

ANDION, Carolina. Análise de redes e desenvolvimento local sustentável. RAP. Rio de Janeiro, n.37, set. 2003.

BARROS, Marinana A.; CEZARIO, Gustavo L. A cooperação descentralizada no Brasil. Disponível em: <http://bit.ly/PtyR1W> Acesso em: 01 set. 2012.

BUARQUE, Sérgio C. Metodologia de planejamento do desenvolvimento local e municipal sustentável. Disponível em: http://www.iica.org.br/Docs/Publicacoes/PublicacoesllCA/SergioBuarque.pdf> Acesso em: 05 dez. 2012.

COELHO, F. Desenvolvimento econômico local no Brasil: Experiências recentes num contexto de descentralização. Documento preparado no âmbito do Projeto Cepal/GTZ "Desarrollo Económico Local y Descentralización en América Latina". Santiago do Chile: Cepal, 2000.

CONFEDERAÇÃO NACIONAL DOS MUNICÍPIOS. As áreas internacionais dos municípios brasileiros. Disponível em: <http://bit.ly/V25UOD> Acesso em: 07 set. 2012.

Divers@! Revista Eletrônica Interdisciplinar/Matinhos/Vol.7, n.1, p. /Jan./jun./2014. 


\section{DIVERS(a!}

DUARTE, Fábio; ULTRAMARI, Clóvis. Desenvolvimento local e regional. Curitiba: Ibpex, 2011.

FIORI. Pedro A.. O ajuste urbano: as políticas do Banco Mundial e BID para as cidades. Revista do Programa de Pós Graduação em Arquitetura e Urbanismo da FAUUSP. São Paulo, n.20, dez. 2006. Disponível em <http://bit.ly/SdYWkX> Acesso em 27 ago. 2012.

FONSECA, Francisco; VIANA, Lucio. Impactos sociais e econômicos da atuação do Banco Interamericano de Desenvolvimento nas políticas públicas. Cadernos do Desenvolvimento. Rio de Janeiro, n.9, jul. 2011.

FRANCO, Augusto de. Desenvolvimento Local Integrado e Sustentável: dez consensos. Proposta. Rio de Janeiro, n.78, set. 1998.

GOLDENSTEIN, L. "Uma avaliação da reestruturação produtiva". In: Sachs, I.; Wilheim, J. \& Pinheiro, P.S. (orgs.). Brasil: Um século de transformações. São Paulo: Companhia das Letras, 2001.

GUESSER, Adauto H.. A influência estratégica das instituições financeiras multilaterais na orientação de políticas no Brasil. Disponível em: <http://bit.ly/Qzp9hj> Acesso em 20 ago. 2012.

MINISTÉRIO DO PLANEJAMENTO, ORÇAMENTO E GESTÃO. Projetos do governo brasileiro financiados com recursos externos. Disponível em:

<http://bit.ly/TIGub3> Acesso em: 01 set. 2012.

MOISÉS, Helvio. O município-rede: Planejamento, desenvolvimento político e sustentabilidade. São Paulo: FPFL-CEPAM, 1999.

STEPHANOU. Michelle C.. Análise comparativa das metodologias de avaliação das agências de fomento internacionais BID e BIRD em financiamentos de projetos sociais no Brasil. Civitas. Porto Alegre, v.5, n.1, p. 127-160, jan.-jun. 2005.

PINTO, S.G.B. "Capacidade e limites à participação dos municípios no financiamento do desenvolvimento urbano". IPPUR/UFRJ. Trabalho Apresentado no XI Encontro da Anpur, Salvador, maio de 2005.

Divers@! Revista Eletrônica Interdisciplinar/Matinhos/Vol.7, n.1, p. /Jan./jun./2014. 
SOARES, Guido F.S. Cooperação Técnica Internacional. In: MARCOVITCH, Jacques (Org.). Cooperação Internacional: estratégia e gestão. São Paulo, 1994, p. 165-218.

TEIXEIRA, Eleonaldo C. O papel das políticas públicas no desenvolvimento local e transformação da realidade. Disponível em: http://www.dhnet.org.br/dados/cursos/aatr2/a_pdf/03_aatr_pp_papel.pdf> Acesso em: 11 jan. 2013.

ULTRAMARI, Clovis. Boas práticas e o fim das utopias urbanas: o terceiro setor e as agências internacionais de financiamento e fomento. 2001. $344 \mathrm{f}$. Tese (Doutorado em Meio ambiente e Desenvolvimento) - Universidade Federal do Paraná, Curitiba, 2001.

VIANNA JR., Aurélio. Estratégias dos bancos Multilaterais para o Brasil: análise crítica e documentos inéditos. Brasília: Rede Brasil sobre Instituições Financeiras Multilaterais, 1998. 